\begin{tabular}{cc} 
Sharif University of Technology \\
Scientia Iranica \\
SCIENTIA & Transactions B: Mechanical Engineering \\
I RAN I CA & \\
\hline
\end{tabular}

\title{
Performance investigation into a diesel engine under effective efficiency-power-power density conditions
}

\author{
G. Gonca* and Y. Palaci \\ Department of Naval Architecture and Marine Engineering, Yildiz Technical University, Besiktas, Istanbul, TR.
}

Received 11 September 2017; received in revised form 5 December 2017; accepted 20 January 2018

\section{KEYWORDS}

Diesel engine;

Diesel cycle;

Compression ignition

engine;

Engine performance;

Power density;

Finite-time

thermodynamics.

\begin{abstract}
Performance analysis of a diesel engine in terms of Effective Power (EP), Effective Power Density (EPD), and Effective Efficiency (EE) has been performed using a novel realistic Finite-Time Thermodynamics (FTT) modeling approach. The effects of design and operating parameters of the diesel cycle, such as bore-stroke length ratio $(d / L)$, Equivalence Ratio (ER), Compression Ratio (CR), Cycle Temperature Ratio (CTR), Cycle Pressure Ratio (CPR), stroke Length $(L)$, friction coefficient (FRC), engine speed $(N)$, mean piston speed, inlet pressure, and inlet temperature, on the engine performance have been investigated. In addition, energy losses depending on Incomplete Combustion (IC), friction losses (FRL), heat transfer losses (HTRL), and Exhaust Output Losses (EOL) have been described as fuel input energy. In order to acquire reasonable results, variable specific heats with respect to temperature for working fluid have been used. The results presented could be an essential tool for diesel engine designers.
\end{abstract}

(C) 2019 Sharif University of Technology. All rights reserved.

\section{Introduction}

Diesel engines are a type of internal combustion engines and they are commonly used in transportation and energy sectors. There are many optimization studies conducted by engine designers to satisfy environmental and economical demands. Engine researchers have studied the optimization of different cycles and different types of engines and energy generation systems [1-26]. In the literature, many studies have been performed related to diesel engines and diesel cycles [27-35]. Gonca [36-40], Gonca and Sahin [4144], and Gonca et al. [45-52] investigated the performance characteristics and emission products of diesel engines with different $\mathrm{NO} x$ reduction methods, such as

\footnotetext{
*. Corresponding author. Tel.: +90 2123832950 ; Fax: +90 212 3832941

E-mail address: ggonca@yildiz.edu.tr (G. Gonca)
}

Miller cycle application and steam injection method. Gonca et al. [45-50] performed a couple of studies on the Miller cycle diesel engines [45-49] and steam injected diesel engines [49-50]. They proved that the Miller cycle and steam injected diesel engines were more advantageous than conventional diesel engine in terms of NO formation. Gonca and Dobrucali [53$54]$ analyzed the performance characteristics of a diesel engine fueled with biodiesel. Gonca [55] also investigated the performance of a spark ignition engine with different fuel types. Al-Hinti et al. [56] used an alternative calculation for heat transfer loss to analyze the performance of an air standard Diesel Cycle (DC). Sakhrieh et al. [57] used a novel gas mixture model in a zero-dimensional single zone combustion simulation to examine the performance characteristics of a DC engine. Durmayaz et al. [58] conducted a review study on the optimization of various thermal systems based on thermoeconomics and finite-time thermodynamics. Hou [59] examined the effects of HTRL loss on the thermal performance of a reversible dual cycle diesel 
engine. Ust et al. [60] expanded the prior study to the irreversible dual cycle diesel engine. Xia et al. [61] examined the performance of a DC by considering some irreversibilities originating from FRL and HTRL losses. Basbous et al. [62] determined the optimum operating parameters, which provided minimum fuel consumption for a diesel engine. Fu et al. [63] experimentally showed that thermal efficiency of a diesel engine could be improved by up to $6.3 \%$ by recovering exhaust gas energy. Jain and Alleyne [64] presented exergy based objective functions for the steady state optimizations of combined energy generation plants. Aydin [65] experimentally examined the possibility of using pure vegetable oils blended petroleum based diesel fuel in a zirconium oxide coating diesel engine. It was shown that $\mathrm{CO}, \mathrm{HC}$, and smoke opacity decreased with the combustion of diesel/vegetable oil mixtures. Li et al. [66] decreased soot, $\mathrm{NO} x$, and CO by using premixed natural gas in a diesel engine. Sprouse and Depcik [67] reviewed Organic Rankine Cycle (ORC) applications to the internal combustion engines for heat recovery using exhaust energy. Lee et al. [68] optimized the performance and emission formations of a diesel engine, which had common rail system, by using analysis of variance and Taguchi methods. They asserted that the optimized novel system provided higher efficiency and lower PM, NOx, and $\mathrm{CO}$ emissions. Debnath et al. [69] researched the emission formation and combustion characteristics of a diesel engine fueled with emulsified biodiesel produced from palm oil. Abedin et al. [70] performed a study on the effects of piston coating material and thickness on the emission formations and performance characteristics of a low-heat rejection diesel engine running with different vegetable oils and biodiesels. Chintala and Subramanian [71] used exergy analysis to assess the maximum useful work of a hydrogen fueled diesel engine. Açkkalp et al. [72] investigated the performance of a diesel-gas engine tri-generation system in Turkey using exergy analysis. They claimed that condenser, high-pressure steam turbine, and combustion chamber had high exergy destruction, so their economic improvement potential was higher than other components of the system.

In this study, the effects of the operating and design parameters on the performance characteristics, such as Effective Power (EP), Effective Power Density (EPD), and Effective Efficiency (EE) as well as energy losses of a DC engine have been parametrically examined using an original realistic FTT model. The presented results have scientific value and they could be assessed by diesel engine designers to obtain optimized conditions of the performance.

\section{Theoretical model}

This study presents a comprehensive analysis of diesel cycle, which is depicted in Figure 1. Computational simulation of EE, EP, and EPD is conducted. In the analyses, a standard condition has been determined. At the standard condition, inlet pressure $\left(P_{1}\right)$ is $100 \mathrm{kPa}$, inlet temperature $\left(T_{1}\right)$ is $300 \mathrm{~K}$, cylinder wall temperature $\left(T_{w}\right)$ is $400 \mathrm{~K}$, Residual Gas Fraction (RGF) is 0.05 , friction coefficient $(\mu)$ is $12.9 \mathrm{Ns} / \mathrm{m}$, cycle temperature ratio $(\alpha)$ is 8 , engine speed $(N)$ is $3600 \mathrm{rpm}$, cylinder bore $(d)$ is $0.072 \mathrm{~m}$, and stroke $(L)$ is $0.062 \mathrm{~m}$. The EP $\left(P_{e f}\right), \operatorname{EPD}\left(P_{d}\right)$, and $\operatorname{EE}\left(\eta_{e f}\right)$ are derived as given below $[20,21,37]$ :

$$
P_{e f}=\dot{Q}_{i n}-\dot{Q}_{o u t}-P_{l}, \quad P_{d}=\frac{P_{e f}}{V_{T}}, \quad \eta_{e f}=\frac{P_{e f}}{\dot{Q}_{f}},
$$

where $\dot{Q}_{i n}$ is the total heat addition at constant pressure (process 2-3) which can be obtained by Eq. (2) as shown in Box I; $\dot{Q}_{\text {out }}$ is the total heat rejection at constant volume (process 4-1) and is obtained by Eq. (3) as shown in Box II; and $P_{l}$ is power loss by friction $[45,73]$, which can be given as follows:

$$
P_{l}=\mu{\overline{S_{P}}}^{2}=\frac{\left[Z+48\left(\frac{N}{1000}\right)+0.4 \bar{S}_{P}^{2}\right] V_{s} N}{1200},
$$
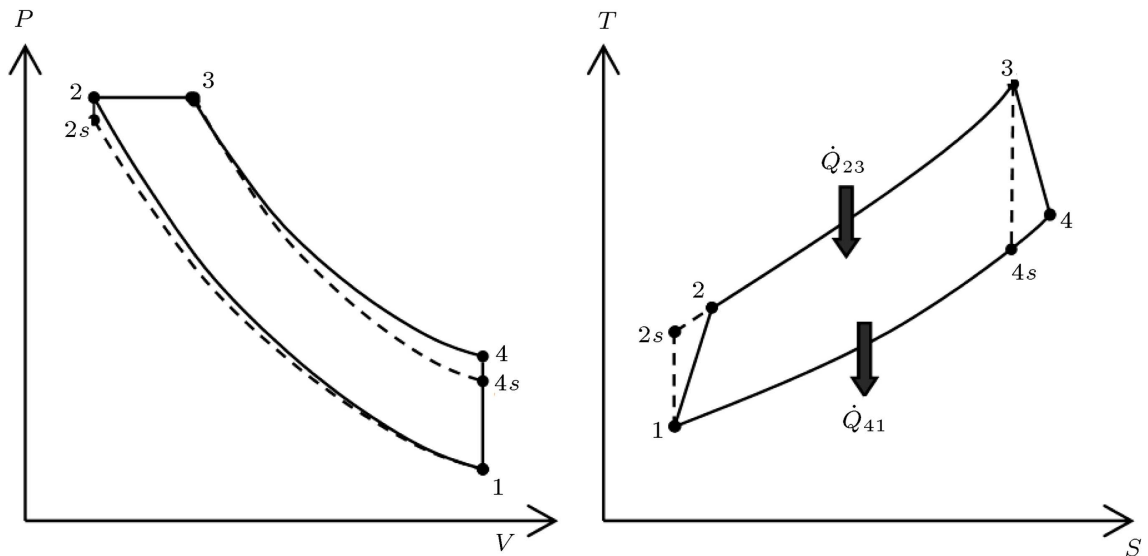

Figure 1. $P-v$ diagram for the irreversible Diesel cycle. 


$$
\begin{aligned}
& \dot{Q}_{i n}=\dot{Q}_{f, c}-\dot{Q}_{h t}=\dot{m}_{T} \int_{T_{2}}^{T_{3}} C_{P} d T \\
& =\left[\dot{m}_{T}\left[\begin{array}{c}
2.506 \cdot 10^{-11} \frac{T^{3}}{3}+1.454 \cdot 10^{-7} \frac{T^{2.5}}{2.5}-4.246 \cdot 10^{-7} \frac{T^{2}}{2}+3.162 \cdot 10^{-5} \frac{T^{1.5}}{1.5}+ \\
1.3303 T-1.512 \cdot 10^{4}\left(-\frac{T^{-0.5}}{0.5}\right)+3.063 \cdot 10^{5}\left(-T^{-1}\right)-2.212 \cdot 10^{7}\left(-\frac{T^{-2}}{2}\right)
\end{array}\right]\right]_{T_{1}}^{T_{4}}
\end{aligned}
$$

Box I

$$
\begin{aligned}
& \dot{Q}_{\text {out }}=\dot{m}_{T} \int_{T_{1}}^{T_{4}} C_{\nu} d T \\
& =\left[\dot{m}_{T}\left[\begin{array}{c}
2.506 \cdot 10^{-11} \frac{T^{3}}{3}+1.454 \cdot 10^{-7} \frac{T^{2.5}}{2.5}-4.246 \cdot 10^{-7} \frac{T^{2}}{2}+3.162 \cdot 10^{-5} \frac{T^{1.5}}{1.5}+ \\
1.0433 T-1.512 \cdot 10^{4}\left(-\frac{T^{-0.5}}{0.5}\right)+3.063 \cdot 10^{5}\left(-T^{-1}\right)-2.212 \cdot 10^{7}\left(-\frac{T^{-2}}{2}\right)
\end{array}\right]\right]_{T_{1}}^{T_{4}}
\end{aligned}
$$

Box II

where $Z$ is friction constant and its minimum value is determined to be 75 [45], $\mu$ is friction coefficient, and $\bar{S}_{p}$ is average piston speed for four stroke engines, which is calculated as follows:

$$
\bar{S}_{p}=\frac{L \cdot N}{30},
$$

where $N$ and $L$ are engine speed (rpm) and stroke length $(\mathrm{m})$, and $\dot{Q}_{f}$ is heat release by combustion of the fuel burned in the cylinder and it is expressed as follows:

$$
\dot{Q}_{f}=\dot{m}_{f} H_{u}
$$

where $H_{u}$ is calorific value or Lower Heating Value (LHV) of the fuel burned in the cylinder; $\dot{m}_{f}$ is fuel mass rate and it may be given as follows:

$$
\dot{m}_{f}=\frac{m_{f} N}{120}
$$

where $m_{f}$ is the mass of the fuel burned in the combustion process per cycle $(\mathrm{kg}), \dot{Q}_{f, c}$ is the heat which is released during the combustion process, and $\dot{Q}_{h t}$ is the heat loss by heat transfer into cylinder wall; they are given as follows:

$$
\begin{aligned}
& \dot{Q}_{f, c}=\eta_{c} \dot{m}_{f} H_{u}, \\
& \dot{Q}_{h t}=h_{t r} A_{c y l}\left(T_{m e}-T_{W}\right)=h_{t r} A_{c y l}\left(\frac{T_{2}+T_{3}}{2}-T_{W}\right),
\end{aligned}
$$

where, $\eta_{c}$ is combustion efficiency. It is given as follows [74-75]:

$$
\eta_{c}=-1,44738+4,18581 / \phi-1,86876 / \phi^{2},
$$

$\phi$ is equivalence ratio and it is expressed as follows:

$$
\phi=\frac{\left(m_{f} / m_{a}\right)}{F_{s t}},
$$

where, $m_{a}$ is the mass of the air, which is introduced into the cylinder $(\mathrm{kg})$, and $F_{\text {st }}[76]$ is stoichiometric fuel/air ratio; they are given as follows:

$$
\begin{aligned}
& m_{a}=\rho_{a} V_{a}=\rho_{a}\left(V_{T}-V_{r g}\right), \\
& V_{T}=V_{s}+V_{c}=\frac{\left(V_{s} r\right)}{r-1} \\
& V_{c}=\frac{V_{T}}{r}=\frac{\pi d^{2} L}{4} \frac{1}{r-1}, \\
& F_{s t}=\frac{\varepsilon \cdot(12.01 \cdot \alpha+1.008 \cdot \beta+16 \cdot \gamma+14.01 \cdot \delta)}{28.85}, \\
& \rho_{a}=f\left(T_{1}, P_{1}\right),
\end{aligned}
$$

where $V_{s}, V_{r g}, V_{a}, V_{c}$, and $V_{T}$ are volumes of stroke, residual gas, air, clearance, and total cylinder. $\rho_{r g}$ is density of residual gas, which is expressed as follows:

$$
\rho_{r g}=f\left(T_{\operatorname{mix}}, P_{1}\right) .
$$

$T_{\text {mix }}$ is mean temperature of air-residual gas in the cylinder. It is calculated as follows:

$$
T_{\text {mix }}=\frac{\dot{m}_{a} T_{1} R_{a}+\dot{m}_{r g} T_{1} R_{r g}}{\dot{m}_{a} R_{a}+\dot{m}_{r g} R_{r g}},
$$


$R_{r g}$ and $R_{a}$ are residual gas constant and air gas constant $(0.287 \mathrm{~kJ} / \mathrm{kg} . \mathrm{K})$, respectively. The compression ratio $(r)$ is given as:

$$
r=V_{1} / V_{2},
$$

where subscript "1" stands for the condition before the compression process. Diesel fuel has been used to model the combustion and thermodynamic processes. The chemical formula of the diesel fuel is given in the literature as $\mathrm{C}_{14.4} \mathrm{H}_{24.9}$ [76]. $\alpha, \beta, \gamma, \delta$ are atomic numbers of $\mathrm{C}, \mathrm{H}, \mathrm{O}$, and $\mathrm{N}$ in the fuel. $\varepsilon$ is molar fuel/air ratio $[76,77]$ :

$$
\varepsilon=\frac{0,21}{\left(\alpha-\frac{\gamma}{2}+\frac{\beta}{4}\right)},
$$

where, $h_{t r}$ is heat transfer coefficient and it is obtained from [78] as follows:

$$
h_{t r}=130 V_{T}^{-0.06} P_{1}^{0.8} T_{\mathrm{mix}}^{0.4}\left(\bar{S}_{p}+1.4\right)^{0.8} .
$$

$A_{c y l}$ is total heat transfer area $\left(\mathrm{m}^{2}\right)$ of the cylinder and $\dot{m}_{r g}, \dot{m}_{a}$, and $\dot{m}_{T}$ are residual gas mass rate $(\mathrm{kg} / \mathrm{s})$, air mass rate $(\mathrm{kg} / \mathrm{s})$, and total cylinder charge mass rate $(\mathrm{kg} / \mathrm{s})$. They are calculated as follows:

$$
\begin{aligned}
& A_{c y l}=\pi d L \frac{r}{r-1}+\frac{\pi d^{2}}{2}, \\
& \dot{m}_{r g}=\frac{m_{r g} N}{120}=\dot{m}_{a} R G F, \\
& \dot{m}_{a}=\frac{m_{a} N}{120}=\frac{\dot{m}_{f} F_{s t}}{\phi}, \\
& \dot{m}_{T}=\dot{m}_{a}+\dot{m}_{f}+\dot{m}_{r g} .
\end{aligned}
$$

$C_{P}$ and $C_{V}$ are constant pressure specific heats, and constant volume respectively, and expressed in the literature as follows [73]:

$$
\begin{aligned}
C_{P}= & 2.506 \cdot 10^{-11} T^{2}+1.454 \cdot 10^{-7} T^{1.5} \\
& -4.246 \cdot 10^{-7} T+3.162 \cdot 10^{-5} T^{0.5} \\
& +1.3303-1.512 \cdot 10^{4} T^{-1.5} \\
& +3.063 \cdot 10^{5} T^{-2}-2.212 \cdot 10^{7} T^{-3}, \\
C_{V}= & C_{P}-R .
\end{aligned}
$$

The process (1-2s) and process $(3-4 \mathrm{~s})$ are reversible adiabatic processes. In the literature, they are given as follows [79]:

$$
\begin{aligned}
& C_{V_{1}} \cdot \ln \left|\frac{T_{2 s}}{T_{1}}\right|=R \ln |r|, \\
& C_{V_{2}} \cdot \ln \left|\frac{T_{4 s}}{T_{3}}\right|=R \cdot \ln \left|\frac{1}{r}\right|,
\end{aligned}
$$

where,

$$
\begin{aligned}
& C_{V_{1}}= 2.506 \cdot 10^{-11} T_{2 s 1}^{2}+1.454 \cdot 10^{-7} T_{2 s 1}^{1.5} \\
&-4.246 \cdot 10^{-7} T_{2 s 1}+3.162 \cdot 10^{-5} T_{2 s 1}^{0.5} \\
&+1.0433-1.512 \cdot 10^{4} T_{2 s 1}^{-1.5} \\
&+3.063 \cdot 10^{5} T_{2 s 1}^{-2}-2.212 \cdot 10^{7} T_{2 s 1}^{-3}, \\
& C_{V_{2}}= 2.506 \cdot 10^{-11} T_{4 s 3}^{2}+1.454 \cdot 10^{-7} T_{4 s 3}^{1.5} \\
&-4.246 \cdot 10^{-7} T_{4 s 3}+3.162 \cdot 10^{-5} T_{4 s 3}^{0.5} \\
&+1.0433-1.512 \cdot 10^{4} T_{4 s 3}^{-1.5} \\
&+3.063 \cdot 10^{5} T_{4 s 3}^{-2}-2.212 \cdot 10^{7} T_{4 s 3}^{-3}, \\
& T_{2 s 1}= \frac{T_{2 s}-T_{1}}{\ln \frac{T_{2 s}}{T_{1}}}, \quad T_{4 s 3}=\frac{T_{4 s}-T_{3}}{\ln \frac{T_{4 s}}{T_{3}}}, \\
& \beta=P_{3} / P_{2}=T_{3} / T_{2} .
\end{aligned}
$$

$\beta$ is pressure ratio. For irreversible conditions, $T_{2}$ and $T_{4}$ could be expressed as follows:

$$
\begin{aligned}
& T_{2}=\frac{T_{2 S}+T_{1}\left(\eta_{C}-1\right)}{\eta_{C}}, \\
& T_{4}=T_{3}+\eta_{E}\left(T_{4 S}-T_{3}\right),
\end{aligned}
$$

where $\eta_{E}$ and $\eta_{C}$ are the isentropic efficiency of the expansion process and isentropic efficiency of the compression process, respectively. The cycle temperature ratio $(\mathrm{CTR}-\alpha)$ and cycle pressure ratio $(\mathrm{CPR}-\lambda)$ are the other dimensionless engine design parameters. They may be expressed, respectively, as:

$$
\begin{aligned}
& \alpha=\frac{T_{\max }}{T_{\min }}=\frac{T_{3}}{T_{1}}=\frac{\lambda}{r}=1+\frac{r^{k-1}-1}{\eta_{C}}, \\
& \lambda=P_{\max } / P_{\min }=P_{3} / P_{1} .
\end{aligned}
$$

The other equations have been taken from [37].

\section{Results and discussion}

In this study, an FTTM has been applied to a DC engine to evaluate the performance characteristics, which are named EP, EPD, and EE.

Figure 2 shows the effects of CTR on the performance characteristics. The maximum EE, EP, and EPD increase with increasing CTR owing to more energy input into cylinder. Higher in-cylinder temperature provides higher combustion efficiency; therefore, $\mathrm{EE}$ and EP increase simultaneously. Increasing EP at constant cylinder volume yields higher EPD. Consequently, all of the performance characteristics improve together. 


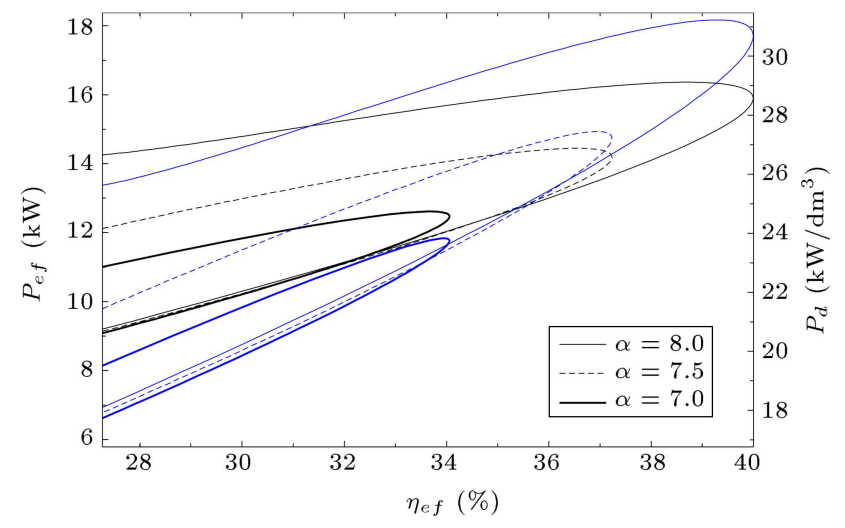

Figure 2. Variations of $P_{e f}, P_{d}$, and $\eta_{e f}$ with respect to $\alpha$.

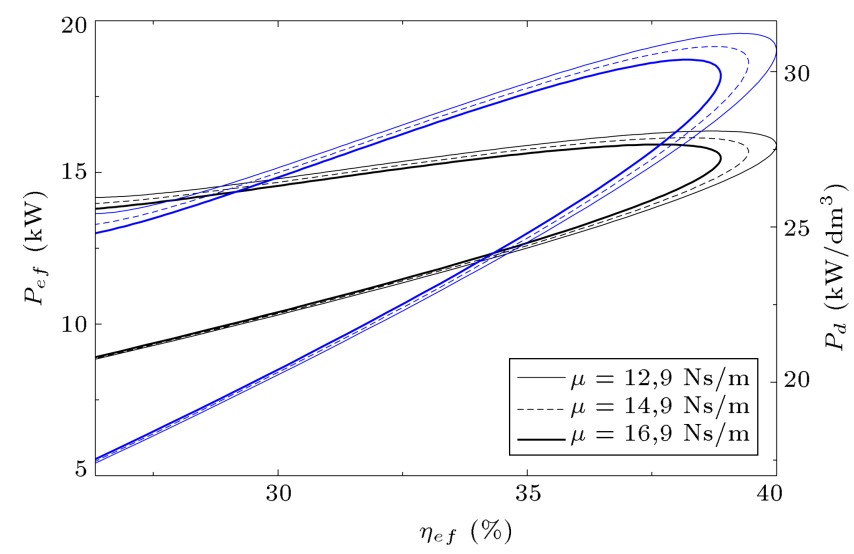

Figure 3. Variations of $P_{e f}, P_{d}$, and $\eta_{e f}$ with respect to $\mu$.

Figure 3 shows the impact of FRC on EP, EPD, and EE. The FRC is related to lubrication oil and in-cylinder surfaces on which friction occurs. FRC increases with enhancing the FRC; hence, performance parameters decrease remarkably. FRC is irreversibility and unwanted; however, it is inevitable and it should be minimized by improving performance characteristics of lubrication oil and friction surfaces.

Figure 4 illustrates the influence of $N$ on the EP, EPD, and EE. $N$ Directly affects the EP as it stands for engine work per time. The EP and EPD rise up with raising engine speed. However, the EE is slightly lower at higher engine speeds as the friction losses increase with enhancing $N$. These results show that increase ratio of the fuel energy introduced into cylinder is slightly higher than that of EP and EPD.

Figure 5 shows the impacts of $\bar{S}_{p}$ on the EP, $\mathrm{EPD}$, and EE. $\bar{S}_{p}$ is related to engine speed and stroke length. Thereby, it affects the performance characteristics and FRL. Figure $5(\mathrm{a})$ is plotted at constant engine speed condition. In this figure, it is shown that all the performance characteristics increase with enhancing $\bar{S}_{p}$. Because engine dimensions (stroke length and bore) increase together, Figure $5(\mathrm{~b})$ is

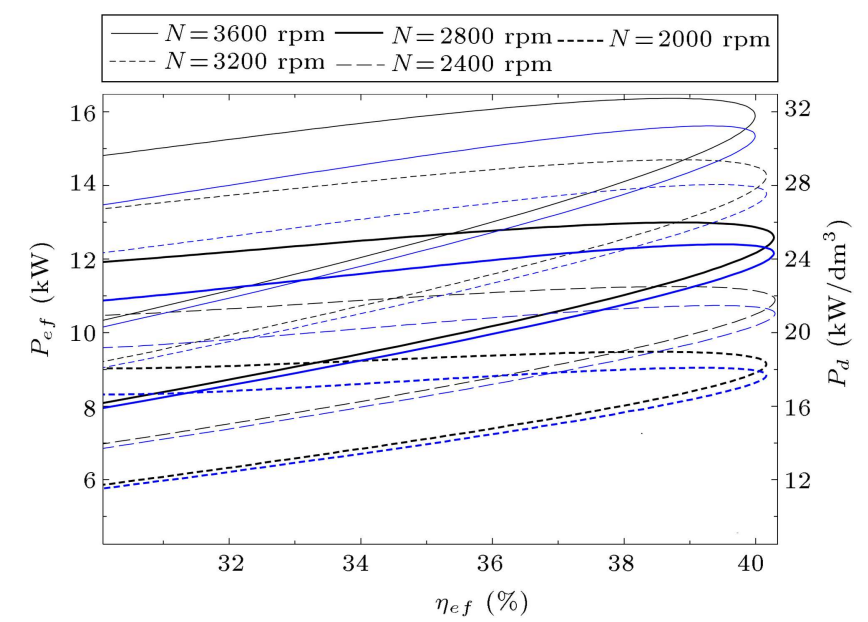

Figure 4. Variations of $P_{e f}, P_{d}$, and $\eta_{e f}$ with respect to $N$.

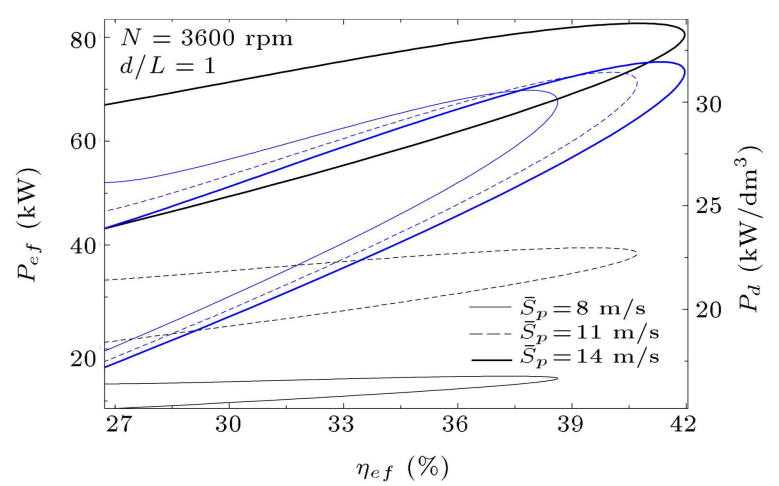

(a)

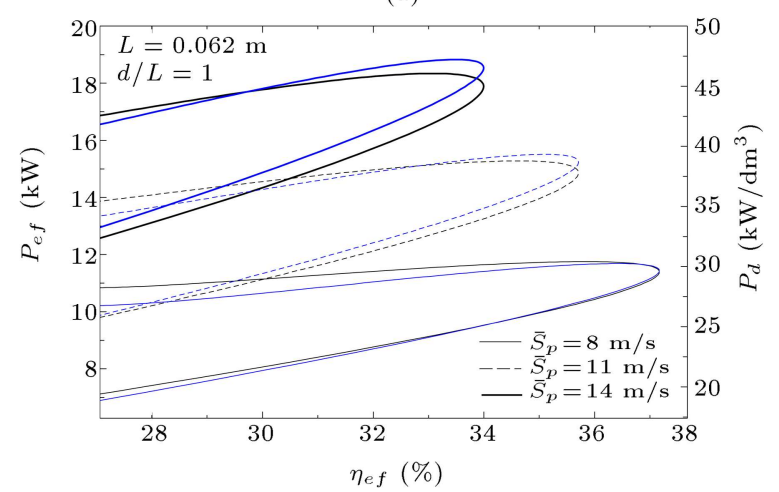

(b)

Figure 5. Variations of $P_{e f}, P_{d}$, and $\eta_{e f}$ with respect to $\bar{S}_{p}$ at fixed (a) $N$, and (b) $L$.

plotted at constant stroke length condition. As the EE decreases, the EP and EPD are enhanced with increasing $\bar{S}_{p}$ at this condition, since engine speed increases. It obviously seems that change of EPD at constant stroke length condition is greater than that at constant engine speed condition, as the change in engine dimensions has similar trend to the change in EP at the constant stroke length condition.

Figure 6 shows the impact of $L$ on the EP, EPD, and EE. $L$ is related to engine dimensions and friction 


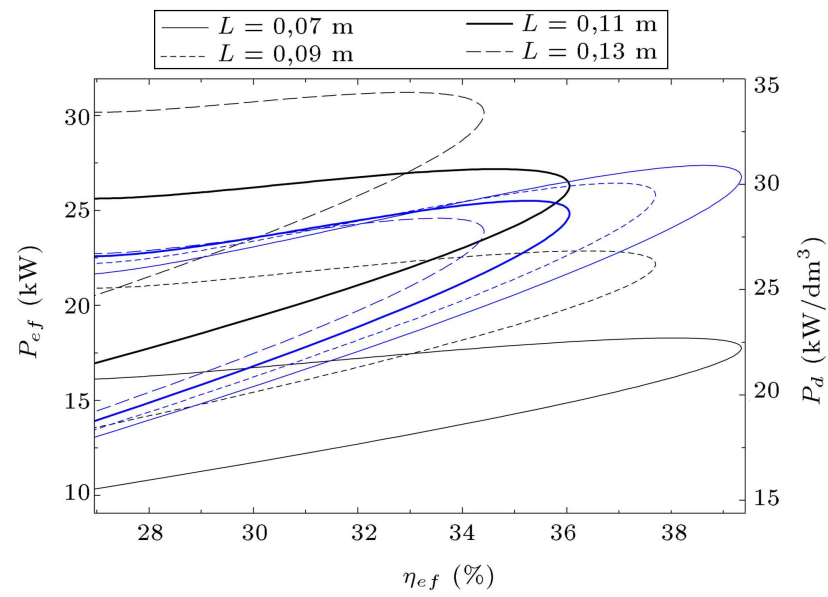

Figure 6. Variations of $P_{e f}, P_{d}$, and $\eta_{e f}$ with respect to $L$.

losses. Increasing $L$ provides higher engine dimensions and, hence, higher power outputs. Also, in-cylinder surface areas are affected by $L$. Therefore, HTRL increases with increasing $L$. It is clear from the figure that EP increases, while EE and EPD decrease, with raising $L$. The main reason for this result is that the friction losses and engine dimensions increase with increase in stroke length. Engine power increases, but the increase in engine dimensions is higher. Therefore, power density decreases with increasing power. Also, it is seen from the figure that the change ratio of EP is higher than that of EPD.

Figure 7(a) and (b) show the effect of air inlet temperature on the EP, EPD, and EE at two different conditions. Figure $7(\mathrm{a})$ is plotted at constant CTR condition. The performance characteristics increase when air inlet temperature increases, since maximum combustion temperature and energy input increase. Figure 7(b) is plotted at constant maximum combustion temperature condition. The performance parameters are minimized with increasing air inlet temperature as the air mass sucked into cylinder diminishes. The air density decreases with enhancing air inlet temperature, so it should be minimized to obtain maximum performance conditions.

Figure 8 illustrates the effect of $\phi$ and $r$ on the CTR and the performance characteristics. $\phi$ and $r$ directly affect in-cylinder combustion temperatures and, hence, CTR. The CTR as well as EP, EPD, and EE increases with enhancing $r$. On the other hand, they increase to a particular value and then begin to decrease with increase in $\phi$, because lower fuel energy input happens at lower values of $\phi$. However, combustion efficiency decreases due to high rates of fuel mass input at higher values of $\phi$. Therefore, at both higher and lower values of $\phi$, deteriorating performance characteristics are observed. These figures indicate that there are optimal points of $\phi$, which yield the maximum performance characteristics and CTR. The

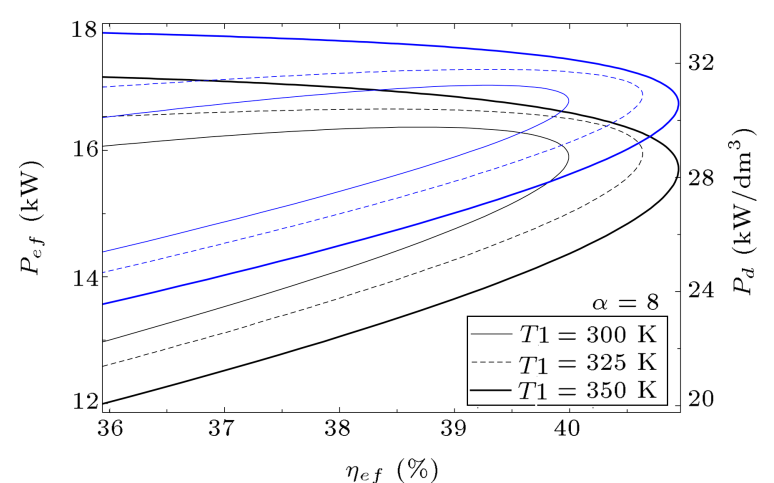

(a)

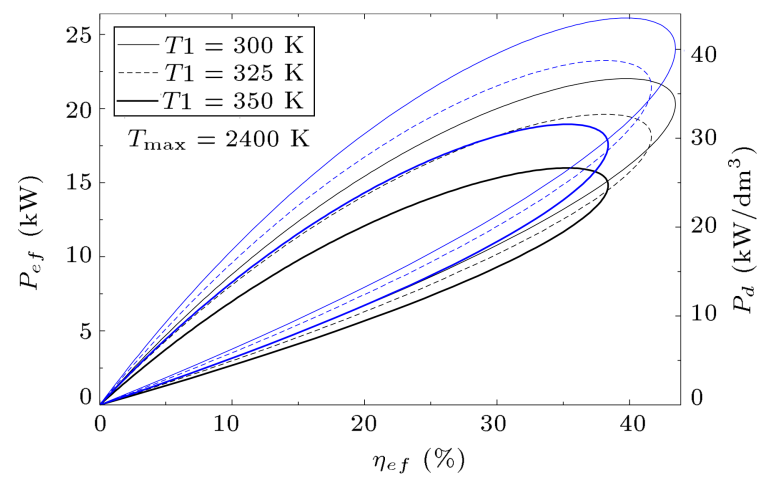

(b)

Figure 7. Variations of $P_{e f}, P_{d}$, and $\eta_{e f}$ with respect to $T 1$ at fixed (a) $\alpha$ and (b) $T_{\max }$.

maximum points of CTR, EP, and EPD are between 1 and $1.2 \phi$, whilst the maximum point of $\mathrm{EE}$ is between 0.8 and $1 \phi$.

Figure 9 shows the influence of $\phi$ on the engine performance. Similar to previous figures, the EP, EPD, and EE increase to certain values of $\phi$ and then begin to decrease. The maximum $\mathrm{EE}$ is seen at $0.9 \phi$ while the maximum EP is seen at 1.2 equivalence ratio since $\phi$ is related to fuel-air amounts and ratios.

Figure 10 shows the effects of wall temperature of the cylinder on the performance characteristics. There are no noticeable changes in maximum effective power and power density depending on cylinder wall temperature. However, maximum effective efficiency decreases with decreasing cylinder wall temperature since heat transfer loss increases with decreasing wall temperature. There is heat transfer between incylinder burned gases and cylinder wall temperature. According to heat transfer law, heat is transferred at high rates at high temperature differences. Therefore, higher cylinder wall temperatures lead to lower heat transfer losses.

Figure 11 demonstrates the influences of air inlet pressure on the EP, EPD, and EE. It is known that more air mass is sucked inside the cylinder at higher pressure conditions. Thus, performance characteristics increase with raising intake pressure. Air density is enhanced with increasing air inlet pressure, so it 


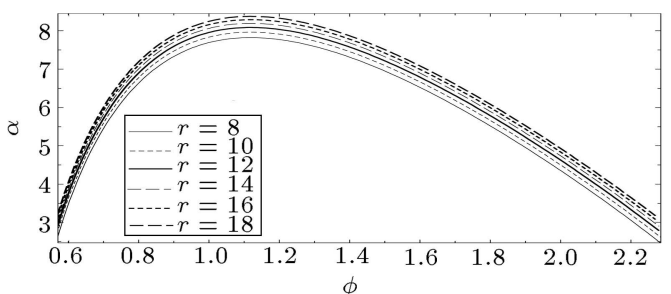

(a)

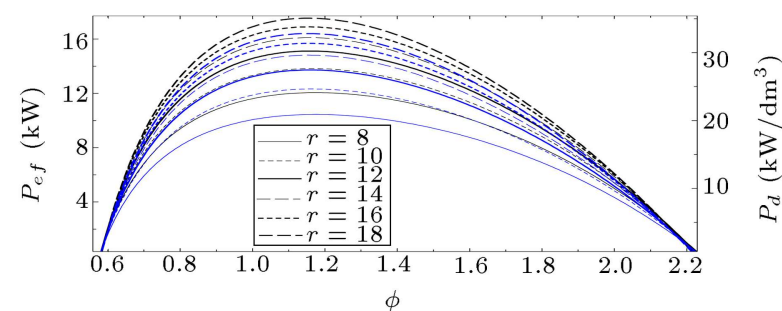

(b)

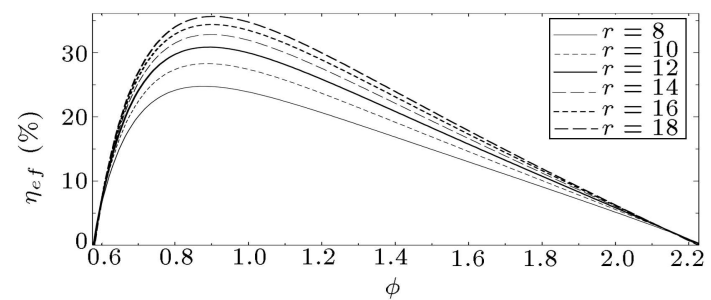

(c)

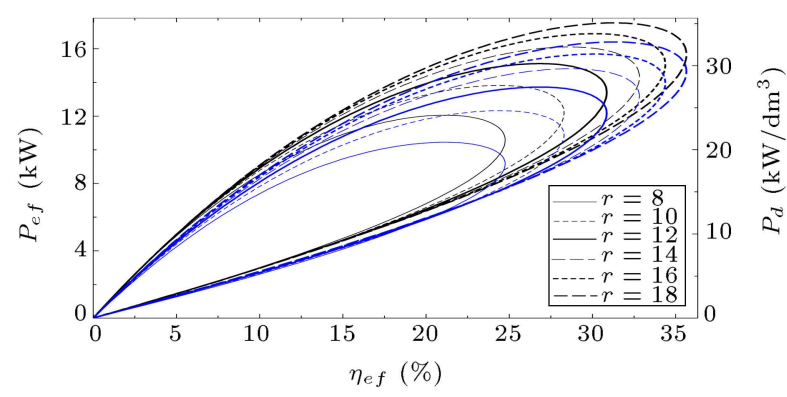

(d)

Figure 8. Variations of (a) $\alpha$, (b) $P_{e f}$ and $P_{d}$, (c) $\eta_{e f}$, and (d) $P_{e f}$ and $\eta_{e f}$ with respect to $r$ and $\phi$.

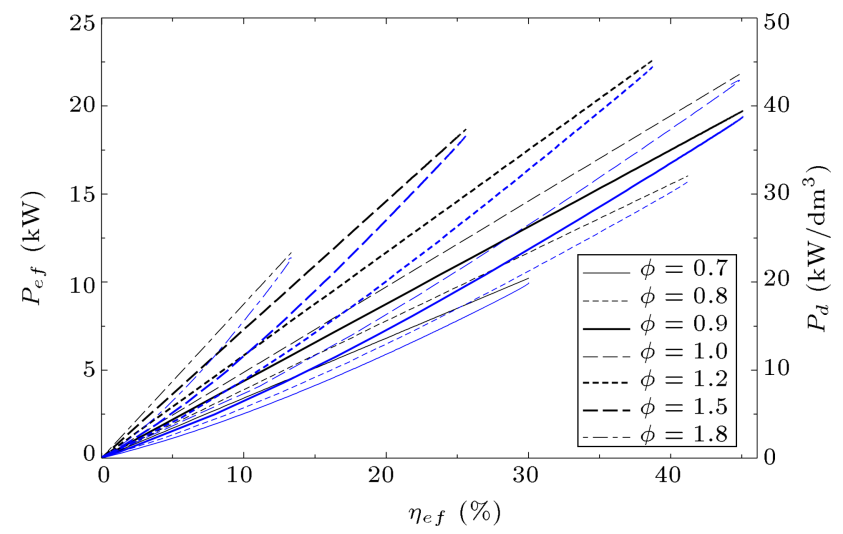

Figure 9. Variations of $P_{e f}, P_{d}$, and $\eta_{e f}$ with respect to $\phi$.

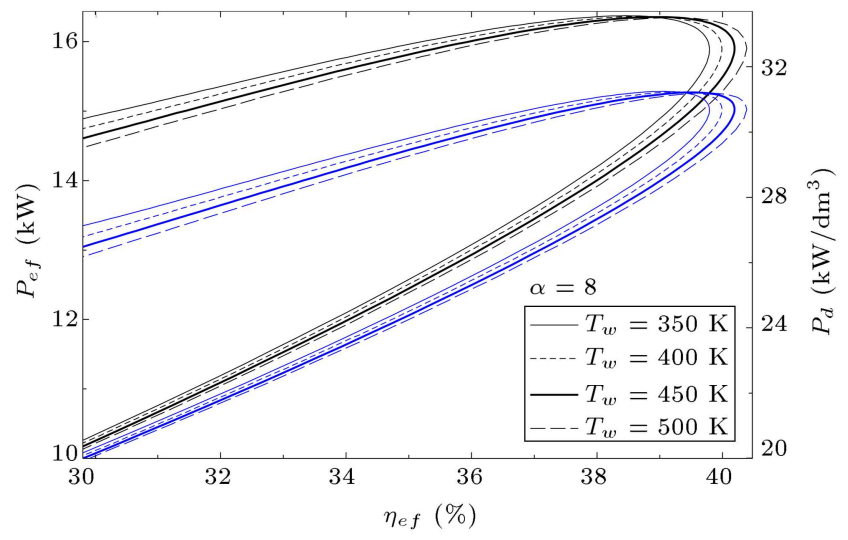

Figure 10. Variations of $P_{e f}, P_{d}$, and $\eta_{e f}$ with respect to $T_{W}$.

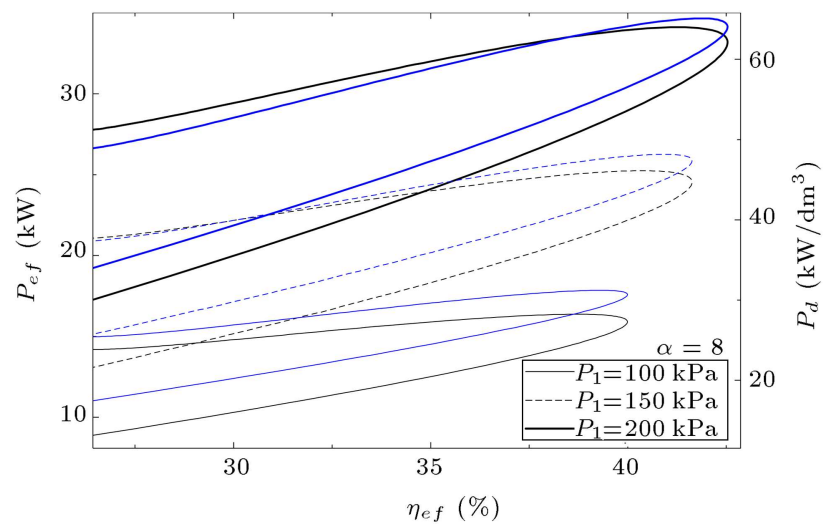

Figure 11. Variations of $P_{e f}, P_{d}$, and $\eta_{e f}$ with respect to $P_{1}$.

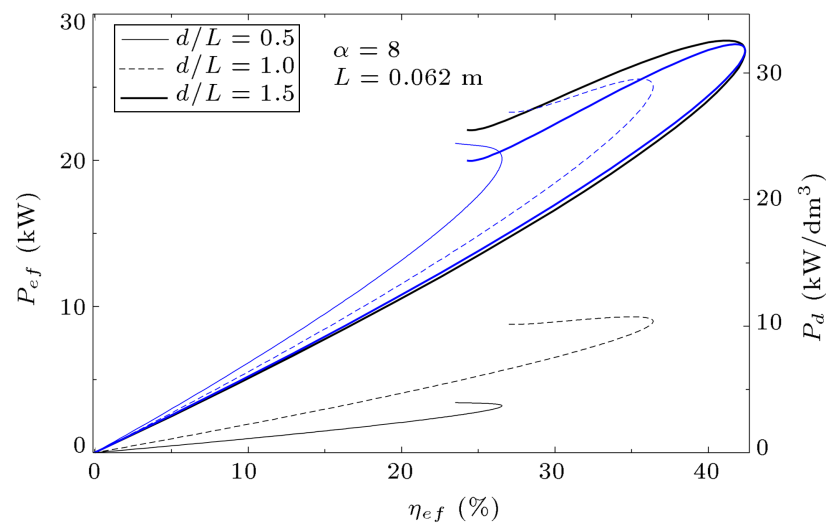

Figure 12. Variations of $P_{e f}, P_{d}$, and $\eta_{e f}$ with respect to $d / L$.

should be maximized to acquire maximum performance specifications.

The influence of $d / L$ on the EP, EPD, and EE at constant CTR and stroke length is illustrated in Figure 12. Due to increase in engine dimensions, the performance characteristics improve with raising $d / L$. Although heat transfer surfaces and heat transfer losses increase with increasing cylinder diameter at high rates, friction losses increase at lower rates. Therefore, 


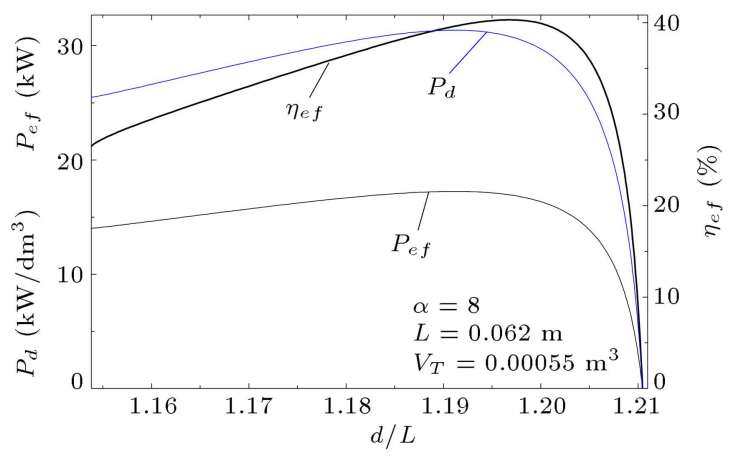

(a)

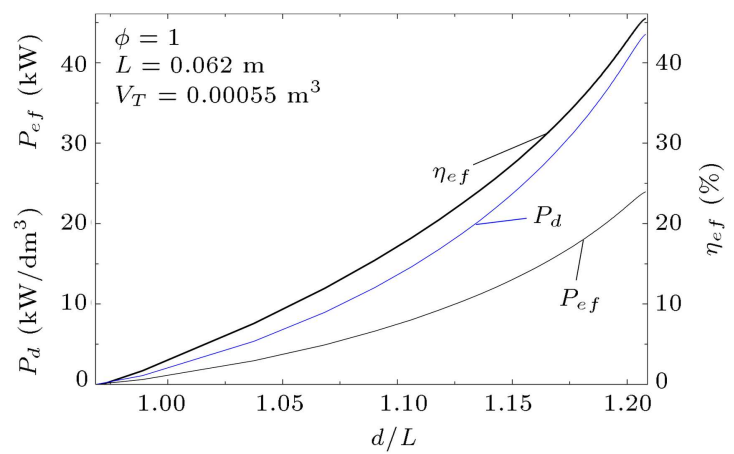

(b)

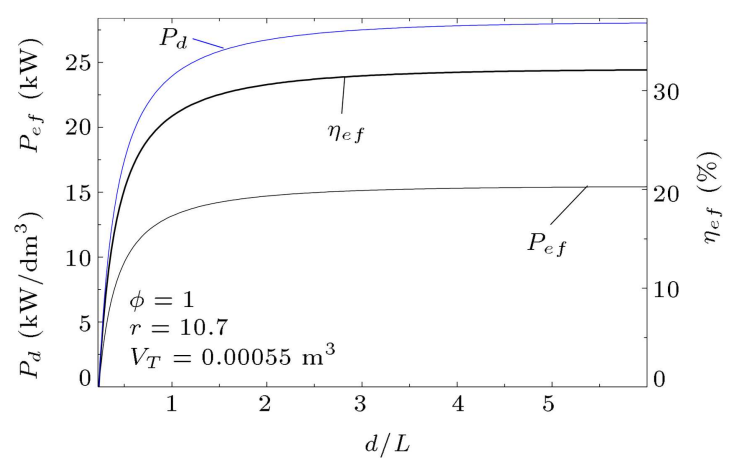

(c)

Figure 13. The effects of $d / L$ on $P_{e f}, P_{d}$, and $\eta_{e f}$ variations at fixed (a) $\alpha$ and $L$, (b) $\phi$ and $L$, and (c) $\phi$ and $r$.

increment of $d$ provides more positive effect than increment of $L$.

Figure 13 shows the effect of $d / L$ on the EP, EPD, and EE at constant cylinder volume for three different conditions. Figure 13(a) is plotted at constant CTR and constant $L$ condition. The performance parameters improve to a determined value and then begin to abate with increase in $d / L$. Figure $13(\mathrm{~b})$ is plotted at constant $\phi$ and $L$ condition. The EP, EPD, and EE rise with increasing $d / L$. Figure $13(\mathrm{c})$ is plotted at constant equivalence ratio and compression ratio condition. This figure shows similar characteristics to the previous figure. The same increase trend is seen.

Figure 14 demonstrates the influence of $r$ on losses as fuel's energy for two different conditions. $r$ affects the performance characteristics and irreversibility. Fig-

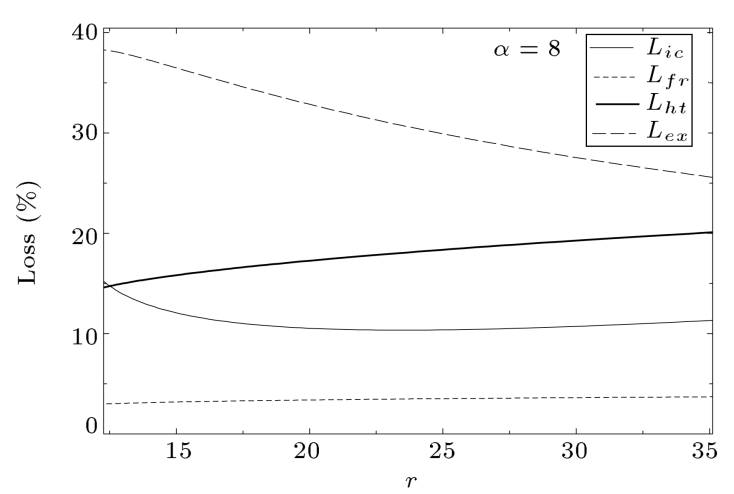

(a)

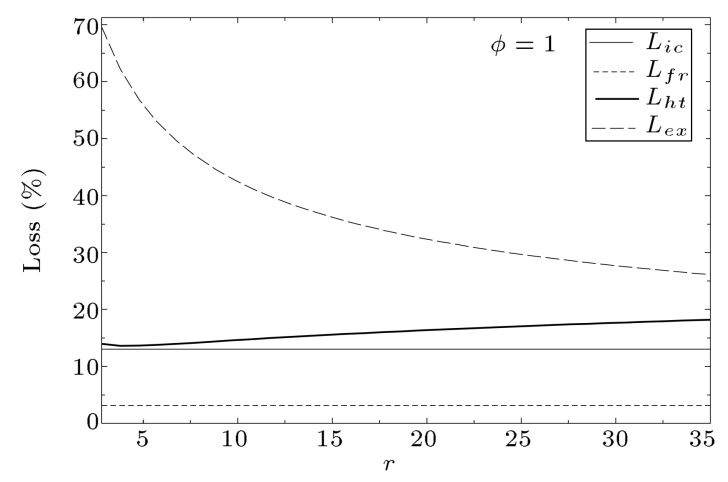

(b)

Figure 14. Variations of energy loss percentages with respect to $r$ at fixed (a) $\alpha$ and (b) $\phi$.

ure 14(a) is depicted at constant cycle temperature ratio condition. Incomplete combustion loss $\left(L_{i c}\right)$ and exhaust energy loss $\left(L_{e x}\right)$ decrease while heat transfer loss $\left(L_{h t}\right)$ increases and friction loss $\left(L_{f r}\right)$ remains constant with increasing $r$. Total cylinder volume and equivalence ratio change with change in $r$ at this condition. $L_{i c}$ is related to equivalence ratio and it changes with changing equivalence ratio. It decreases as fuel energy input decreases with increasing $r$. Figure $14(\mathrm{~b})$ is depicted at constant equivalence ratio condition. $L_{i c}$ and $L_{f r}$ are constant, $L_{h t}$ increases and $L_{e x}$ decreases by enhancing $r . \quad V_{T}$ increases by increasing $r$, hence $L_{h t}$ increases. Useful work increases by increasing $r$ and so $L_{e x}$ is diminished. $L_{f r}$ changes with $L$ and $N$, which are constant at both of the conditions. Therefore, $L_{i c}$ does not change.

Figure 15 demonstrate the effects of RGF on the performance parameters for three different conditions. The RGF is negative performance parameter. It leads to decreasing air density and air mass. The figures are plotted at constant cycle temperature condition, at constant equivalence ratio condition, and at constant compression ratio condition. Similar trends are seen for all circumstances. The EP, EPD, and EE decrease with increasing RGF, since air inlet temperature increases and the air mass introduced inside the cylinder decreases by increasing RGF. However, maximum combustion temperatures are diminished by 


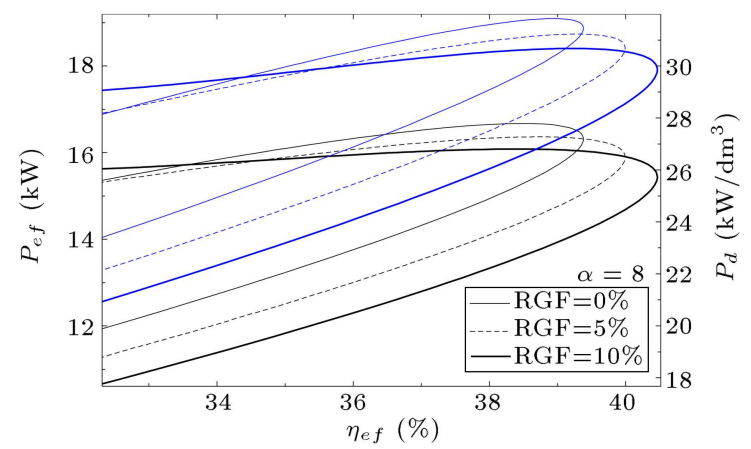

(a)

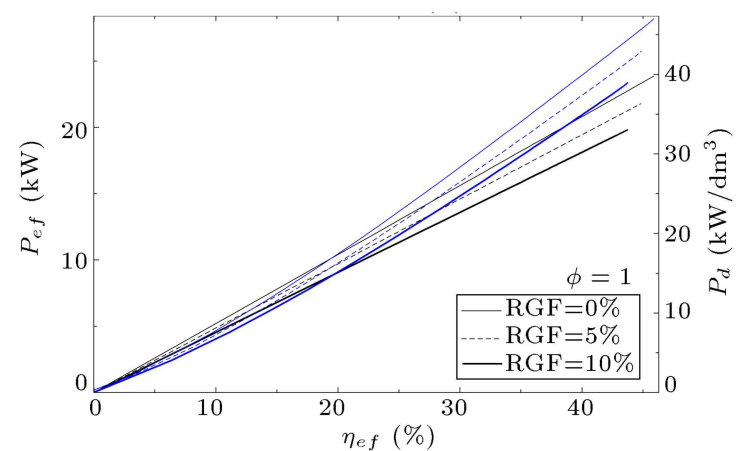

(b)

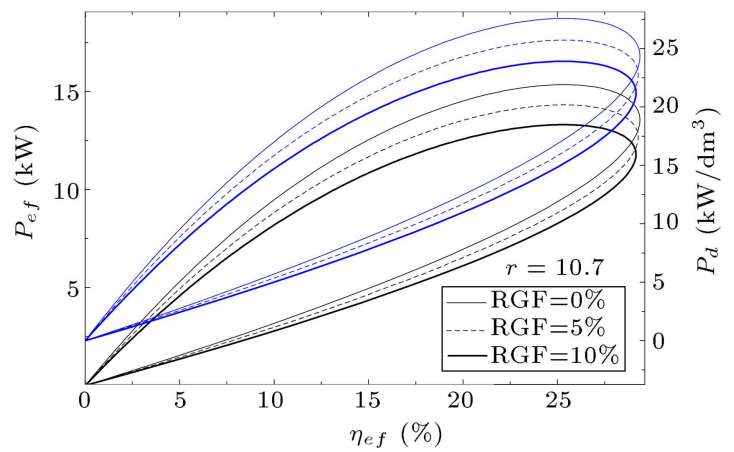

(c)

Figure 15. The effects of RGF on $P_{e f}, P_{d}$, and $\eta_{e f}$ variations at fixed (a) $\alpha$, (b) $\phi$, and (c) $r$.

raising $\mathrm{RGF}$ due to reduction in oxygen concentrations. Also, NOx emissions decrease by increasing RGF, since NOx formations are observed at high combustion temperatures.

\section{Conclusion}

A comprehensive parametrical study was performed for the DC engine. The influences of air inlet temperature (T1), air inlet pressure (P1), $\operatorname{CTR}(\alpha), \operatorname{CPR}(\lambda)$, FR coefficient $(\mu)$, engine speed $(N)$, average piston speed $\left(\bar{S}_{p}\right)$, stroke length $(L)$, compression ratio $(r)$, equivalence ratio $(\phi)$, bore-stroke length ratio $(d / L)$, and Residual Gas Fraction (RGF) on the performance characteristics were examined. The results showed that the performance characteristics improved with increase in $\operatorname{CTR}(\alpha), \operatorname{CPR}(\lambda)$, and air inlet pressure $(\mathrm{P} 1)$. The performance characteristics decreased by increasing FR coefficient $(\mu)$; however, EP, EPD, and EE improved with increase in mean piston speed in constant engine speed conditions. On the other hand, as the EP and EPD improved, the EE was diminished with increase in $\bar{S}_{p}$ at constant $L$ circumstance. While the EP and EPD increased, the EE decreased with increase in $L$ and $N$. The EP, EPD, and EE increased up to a determined value and then began to decrease by raising $\phi$ and $r$. The energy losses with respect to heat transfer increased, as incomplete combustion and exhaust output losses were minimized with increase in $r$ at constant $\alpha$ circumstance. At this condition, friction losses were constant. Moreover, the losses of FR and IC were constant, whilst exhaust output loss decreased and HT losses increased at constant $\phi$ condition. The results have scientific value and they could be used by DC engine designers and manufacturers to obtain optimized engine operating and design conditions.

\section{Nomenclature}

$\begin{array}{ll}A & \text { Heat transfer area }\left(\mathrm{m}^{2}\right) \\ \text { CR } & \text { Compression Ratio } \\ C_{v} & \text { Constant volume specific heat } \\ & \text { (kJ/kg.K) } \\ C_{p} & \text { Constant pressure specific heat } \\ & \text { (kJ/kg.K) } \\ \text { CPR } & \text { Cycle Pressure Ratio } \\ \text { CTR } & \text { Cycle Temperature Ratio } \\ d & \text { Bore (m) } \\ d / L & \text { Bore-stroke length ratio } \\ \text { EE } & \text { Effective Efficiency } \\ \text { EOL } & \text { Exhaust Output Losses } \\ \text { EP } & \text { Effective Power } \\ \text { EPD } & \text { Effective Power Density } \\ \text { ER } & \text { Equivalence Ratio } \\ F & \text { Fuel-air ratio } \\ \text { FRC } & \text { Friction coefficient } \\ \text { FRL } & \text { Friction losses } \\ \text { FTT } & \text { Finite-Time Thermodynamics } \\ \text { HTRL } & \text { Heat transfer losses } \\ h_{t r} & \text { Heat transfer coefficient }\left(\mathrm{W} / \mathrm{m}{ }^{2} \mathrm{~K}\right) \\ H & \text { Lower heat value of the fuel }(\mathrm{kJ} / \mathrm{kg}) \\ \text { IC } & \text { Incomplete Combustion } \\ \text { ICE } & \text { Internal Combustion Engine } \\ l & \text { Loss } \\ L & \text { Stroke length (m), energy loss } \\ m & \text { percentage (\%) } \\ & \text { Mass (kg) } \\ & \end{array}$




$\begin{array}{ll}\dot{m} & \text { Time- dependent mass rate }(\mathrm{kg} / \mathrm{s}) \\ N & \text { Engine speed }(\mathrm{rpm}) \\ P & \text { Pressure }(\text { bar }), \text { power }(\mathrm{kW}) \\ \dot{Q} & \text { Rate of heat transfer }(\mathrm{kW}) \\ r & \text { Compression ratio } \\ R & \text { Gas constant }(\mathrm{kJ} / \mathrm{kg} . \mathrm{K}) \\ \mathrm{RGF} & \text { Residual Gas Fraction } \\ S & \text { Stroke }(\mathrm{m}) \\ \bar{S}_{p} & \text { Mean piston speed }(\mathrm{m} / \mathrm{s}) \\ T & \text { Temperature }(\mathrm{K}) \\ v & \text { Specific volume }\left(\mathrm{m}^{3} / \mathrm{kg}\right) \\ V & \text { Volume }\left(\mathrm{m}^{3}\right)\end{array}$

\section{Greek letters}

$\alpha \quad$ Cycle temperature ratio, atomic number of carbon

$\beta \quad$ Pressure ratio, atomic number of hydrogen

$\sigma \quad$ Atomic number of nitrogen

$\phi \quad$ Equivalence ratio

$\gamma \quad$ Atomic number of oxygen

$\lambda \quad$ Cycle pressure ratio

$\mu \quad$ Friction coefficient $\left(\mathrm{Ns}_{\mathrm{s}} / \mathrm{m}\right)$

$\rho \quad$ Density $\left(\mathrm{kg} / \mathrm{m}^{3}\right)$

\section{Subscripts}

l

At the beginning of the compression process

a Air

$c \quad$ Combustion, clearance

cyl Cylinder

ef Effective

$f \quad$ Fuel

fr Friction

$h t \quad$ Heat Transfer

$i \quad$ Initial condition

ic Incomplete combustion

in Input

$l \quad$ Loss

$\max \quad$ Maximum

me Mean

min Minimum

mix Mixture

out Output

rg Residual Gas

$s \quad$ Stroke, isentropic condition

st Stoichiometric $\begin{array}{ll}t & \text { Total } \\ w & \text { Cylinder walls }\end{array}$

\section{References}

1. Al-Sarkhi, A., Al-Hinti, I., Abu-Nada, E., and Akash, B. "Performance evaluation of irreversible Miller engine under various specific heat models", Int. Commun. Heat Mass., 34, pp. 897-906 (2007).

2. Al-Sarkhi, A., Akash, B., Abu-Nada, E., and Al-Hinti I. "Efficiency of Atkinson engine at maximum power density using temperature dependent specific heats", JJMIE, 2, pp. 71-75 (2008).

3. Ge, Y., Chen, L., and Sun, F. "Finite-time thermodynamic modeling and analysis for an irreversible dual cycle", Math. Comput. Model., 50, pp. 101-108 (2009).

4. Gonca, G. "Thermo-ecological analysis of irreversible dual-miller cycle (DMC) engine based on the ecological coefficient of performance (ECOP) criterion", Iran J. Sci. Technol. Trans. Eng., 41, pp. 269-280 (2017).

5. Ebrahimi, R. "Effects of equivalence ratio and mean piston speed on performance of an irreversible dual cycle", Acta Physica Polonica A, 120(3), pp. 384-389 (2011).

6. Ebrahimi, R. "Effect of expansion-compression ratio on performance of the miller cycle", Acta Physica Polonica A, 122(4), pp. 645-649 (2012).

7. Ebrahimi, R. "Performance analysis of an irreversible Miller cycle with considerations of relative air-fuel ratio and stroke length", Applied Mathematical Modelling, 36, pp. 4073-4079 (2012).

8. Ebrahimi, R. "Thermodynamic modeling of an Atkinson cycle with respect to relative air-fuel ratio, fuel mass flow rate and residual gases", Acta Physica Polonica A, 124(1), pp. 29-34 (2013).

9. Gahruei, M.H., Jeshvaghani, H.S., Vahidi, S., and Chen, L. "Mathematical modeling and comparison of air standard dual and dual-Atkinson cycles with friction, heat transfer and variable specific-heats of the working fluid", Applied Mathematical Modelling, 37, pp. 7319-7329 (2013).

10. Shadloo, M.S., Poultangarib, R., Abdollahzadeh, Jamalabadi, M.Y., and Rashidi, M.M. "A new and efficient mechanism for spark ignition engines", Energy Convers Manage, 96, pp. 418-429 (2015).

11. Mousapour, A., Hajipour, A., Rashidi, M.M., and Freidoonimehr, N. "Performance evaluation of an irreversible Miller cycle comparing FTT (finite-time thermodynamics) analysis and ANN (artificial neural network) prediction", Energy, 94, pp. 100-109 (2016).

12. Gonca, G. "Exergetic and thermo-ecological performance analysis of a gas-Mercury combined turbine system (GMCTS)", Energy Conversion and Management, 151, pp. 32-42 (2017).

13. Gonca, G. "Exergetic and ecological performance analyses of a gas turbine system with two intercoolers and two re-heaters", Energy, 124, pp. 579-588 (2017). 
14. Gonca, G. and Sahin, B. "Thermo-ecological performance analysis of a Joule-Brayton cycle (JBC) turbine with considerations of heat transfer losses and temperature-dependent specific heats", Energy Conversion and Management, 138, pp. 97-105 (2017).

15. Gonca, G. "Investigation of the effects of steam injection on performance and NO emissions of a diesel engine running with ethanol-diesel blend", Energy Conversion and Management, 77, pp. 450-457 (2014).

16. Kökkülünk, G., Gonca, G., Ayhan, V., Cesur, I., and Parlak, A. "Theoretical and experimental investigation of diesel engine with steam injection system on performance and emission parameters", Applied Thermal Engineering, 54, pp. 161-170 (2013).

17. Cesur, I., Parlak, A., Ayhan, V., Boru, B., and Gonca, G. "The effects of electronic controlled steam injection on spark ignition engine", Applied Thermal Engineering, 55, pp. 61-68 (2013).

18. Gonca, G., Sahin, B., Parlak, A., Ayhan, V., Cesur, I., and Koksal, S. "Application of the Miller cycle and turbo charging into a diesel engine to improve performance and decrease NO emissions", Energy, 93, pp. 795-800 (2015).

19. Kökkülünk, G., Parlak, A., Ayhan, V., Cesur, I., Gonca, G., and Boru, B. "Theoretical and experimental investigation of steam injected diesel engine with EGR", Energy, 74, pp. 331-339 (2014).

20. Gonca, G. "Performance analysis of an Atkinson cycle engine under effective power and effective power density conditions", Acta Physica Polonica A, 132, pp. 1306-1313 (2017).

21. Gonca, G. "An optimization study on an eco-friendly engine cycle named as dual-miller cycle (DMC) for marine vehicles", Polish Maritime Research, 24, pp. 86-98 (2017).

22. Gonca, G. "Energy and exergy analyses of single and double reheat irreversible Rankine cycle", International Journal of Exergy, 18, pp. 402-422 (2015).

23. Kökkülünk, G., Gonca, G., and Parlak, A. "The effects of design parameters on performance and NO emissions of steam-injected diesel engine with exhaust gas recirculation", Arabian Journal For Science and Engineering, 39, pp. 4119-4129 (2014).

24. Gonca, G. and Sahin, B. "Performance optimization of an air-standard irreversible dual-atkinson cycle engine based on the ecological coefficient of performance criterion", Scientific World Journal, 815787, pp. 1-10 (2014).

25. Gonca, G., Sahin, B., Ust, Y., and Parlak, A. "Determination of the optimum temperatures and mass ratios of steam injected into turbocharged internal combustion engines", Journal of Renewable and Sustainable Energy, 5, 023119, pp. 1-13 (2013).

26. Ust, Y., Gonca, G., and Kayadelen H.K. "Determination of optimum reheat pressures for single and double reheat irreversible Rankine cycle", Journal of the Energy Institute, 84, pp. 215-219 (2011).
27. Chen, L., Zeng, F., Sun, F., and Wu, C. "Heat transfer effect on net work and/or power as function of efficiency for air-standard Diesel cycles", Energy, 21(12), pp. 1201-1205 (1996).

28. Chen, L., Lin, J., Luo, J., Sun, F., and Wu, C. "Friction effect on the characteristic performance of diesel cycles", Int. J. Energy Res., 26(11), pp. 965-971 (2002).

29. Ge, Y., Chen, L., Sun, F., and Wu, C. "Performance of Diesel cycle with heat transfer, friction and variable specific heats of working fluid", J. Energy Inst., 80(4), pp. 239-242 (2007).

30. Ge, Y., Chen, L., Sun, F., and Wu, C. "Performance of an endoreversible Diesel cycle with variable specific heats of working fluid", Int. J. Ambient Energy, 29(3), pp. 127-136 (2008).

31. Ge, Y., Chen, L., and Sun, F. "Finite time thermodynamic modeling and analysis for an irreversible Diesel cycle", Proc. IMechE, Part D: J. Automob. Eng., 222(D5), pp. 887-894 (2008).

32. Ge, Y., Chen, L., and Sun, F. "Optimal paths of piston motion of irreversible Diesel cycle for minimum entropy generation", Therm. Sci., 15(4), pp. 975-993 (2011).

33. Chen, L., Xia, S., and Sun, F. "Optimizing piston velocity profile for maximum work output from a generalized radiative law Diesel engine", Math. Comput. Model., 54(9-10), pp. 2051-2063 (2011).

34. Xia, S., Chen, L., and Sun, F. "Engine performance improved by controlling piston motion: linear phenomenological law system Diesel cycle", Int. J. Therm. Sci., 51(1), pp. 163-174 (2012).

35. Ge, Y., Chen, L., and Sun, F. "Progress in finite time thermodynamic studies for internal combustion engine cycles", Entropy, 18(4), p. 139 (2016).

36. Gonca, G. "Effects of engine design and operating parameters on the performance of a spark ignition (SI) engine with steam injection method (SIM)", Applied Mathematical Modelling, 44, pp. 655-675 (2017).

37. Gonca, G. "Thermodynamic analysis and performance maps for the irreversible Dual-Atkinson cycle engine (DACE) with considerations of temperaturedependent specific heats, heat transfer and friction losses", Energy Conversion and Management, 111, pp. 205-216 (2016).

38. Gonca, G. "Performance analysis and optimization of irreversible Dual-Atkinson cycle engine (DACE) with heat transfer effects under maximum power and maximum power density conditions", Applied Mathematical Modelling, 40, pp. 6725-6736 (2016).

39. Gonca, G. "Comparative performance analyses of irreversible OMCE (Otto Miller cycle engine)-DiMCE (Diesel Miller cycle engine)-DMCE (dual Miller cycle engine)", Energy, 109, pp. 152-159 (2016).

40. Gonca, G. "Investigation of the influences of steam injection on the equilibrium combustion products and thermodynamic properties of bio fuels (biodiesels and alcohols)", Fuel, 144, pp. 244-258 (2015). 
41. Gonca, G. and Sahin, B. "Simulation of performance and nitrogen oxide formation of a hydrogen-enriched diesel engine with the steam injection method", Thermal Science, 19, pp. 1985-1994 (2015).

42. Gonca G., and Şahin B. "The influences of the engine design and operating parameters on the performance of a turbocharged and steam injected diesel engine running with the Miller cycle", Applied Mathematical Modelling, 40, pp. 3764-3782 (2016).

43. Gonca, G. and Şahin B. "Thermo-ecological performance analyses and optimizations of irreversible gas cycle engines", Applied Thermal Engineering, 105, pp. 566-576 (2016).

44. Gonca, G. and Şahin B. "Effect of turbo charging and steam injection methods on the performance of a Miller cycle diesel engine (MCDE)", Applied Thermal Engineering, 118, pp. 138-146 (2017).

45. Gonca, G., Sahin, B., Ust, Y., and Parlak, A. "A study on late intake valve closing Miller cycled diesel engine", Arab. J. Sci. Eng., 38, pp. 383-393 (2013).

46. Gonca, G., Sahin, B., and Ust, Y. "Performance maps for an air-standard irreversible dual-Miller cycle (DMC) with late inlet valve closing (LIVC) version", Energy, 5, pp. 285-290 (2013).

47. Gonca, G., Sahin, B., and Ust, Y. "Investigation of heat transfer influences on performance of airstandard irreversible dual-Miller cycle", Journal of Thermophysics and Heat Transfer, 29, pp. 678-683 (2015).

48. Gonca, G., Şahin, B., Parlak, A., Üst, Y., Ayhan, V., Cesur, I., and Boru, B. "Theoretical and experimental investigation of the Miller cycle diesel engine in terms of performance and emission parameters", Applied Energy, 138, pp. 11-20 (2015).

49. Gonca, G., Şahin, B., Üst, Y., Parlak, A., and Safa, A. "Comparison of steam injected diesel engine and Miller cycled diesel engine by using two zone combustion model", Journal of the Energy Institute, 88, pp. 43$52(2015)$.

50. Gonca, G., Sahin, B., Parlak, A., Ust, Y., Ayhan, V., Cesur, I., and Boru, B. "The effects of steam injection on the performance and emission parameters of a Miller cycle Diesel engine", Energy, 78, pp. 266275 (2014)

51. Gonca, G., Şahin, B., Üst, Y., and Parlak, A. "Comprehensive performance analyses and optimization of the irreversible thermodynamic cycle engines (TCE) under maximum power (MP) and maximum power density (MPD) conditions", Applied Thermal Engineering, 85, pp. 9-20 (2015).

52. Gonca, G., Şahin, B., Parlak, A., Ayhan, V., Cesur I., and Koksal, S. "Investigation of the effects of the steam injection method (SIM) on the performance and emission formation of a turbocharged and Miller cycle diesel engine (MCDE)", Energy, 119, pp. 926937 (2017).
53. Gonca, G. and Dobrucali, E. "Theoretical and experimental study on the performance of a diesel engine fueled with diesel-biodiesel blends", Renewable Energy, 93, pp. 658-666 (2016).

54. Gonca, G. and Dobrucali, E. "The effects of engine design and operating parameters on the performance of a diesel engine fueled with diesel-biodiesel blends", Journal of Renewable and Sustainable Energy, 8(025702), pp. 1-13 (2016).

55. Gonca, G. "Influences of different fuel kinds and engine design parameters on the performance characteristics and NO formation of a spark ignition (SI) engine", $A p$ plied Thermal Engineering, 127, pp. 194-202 (2017).

56. Al-Hinti, I., Akash, B., Abu-Nada, E., and Al-Sarkhi, A. "Performance analysis of air-standard Diesel cycle using an alternative irreversible heat transfer approach", Energy Convers. Manage., 49(11), pp. 33013304 (2008).

57. Sakhrieh, A., Abu-Nada, E., Akash, B., Al-Hinti, I., and Al-Ghandoor, A. "Performance of a diesel engine using a gas mixture with variable specific heats model", J. Energy Inst., 83, pp. 217-224 (2010).

58. Durmayaz, A., Sogut, O.S., Sahin, B., and Yavuz, H., "Optimization of thermal systems based on finite-time thermodynamics and thermoeconomics", Prog. Energ. Combust. Sci., 30, pp. 175-217 (2004).

59. Hou, S.S. "Heat transfer effects on the performance of an air standard dual cycle", Energy Conversion and Management, 45(18-19), pp. 3003-3015 (2004).

60. Ust, Y., Sahin, B., Gonca, G., and Kayadelen, H.K. "Heat transfer effects on the performance of an airstandard irreversible dual cycle", International Journal of Vehicle Design, 63(1), pp. 102-116 (2013).

61. Xia, S., Chen, L., and Sun, F. "Engine performance improved by controlling piston motion: Linear phenomenological law system Diesel cycle", International Journal of Thermal Sciences, 51, pp. 163-174 (2012).

62. Basbous, T., Younes, R., Ilinca, A., and Perron, J. "Pneumatic hybridization of a diesel engine using compressed air storage for wind-diesel energy generation", Energy, 38(1), pp. 264-275 (2012).

63. Fu, J., Liu, J., Ilinca, A., Ren, C., Wang, L., Deng, B., and $\mathrm{Xu}, \mathrm{Z}$. "An open steam power cycle used for IC engine exhaust gas energy recovery", Energy, 44(1), pp. 544-554 (2012).

64. Jain, N. and Alleyne, A.G. "A framework for the optimization of integrated energy systems", Applied Thermal Engineering, 48, pp. 495-505 (2012).

65. Aydin, H. "Combined effects of thermal barrier coating and blending with diesel fuel on usability of vegetable oils in diesel engines", Applied Thermal Engineering, 51(1-2), 623-629 (2013).

66. Li, J., Yang, W.M., Goh, T.N., An, H., and Maghbouli, A. "Adjusting the operating characteristics to improve the performance of an emulsified palm oil methyl ester run diesel engine", Energy Conversion and Management, 69, pp. 191-198 (2013). 
67. Sprouse, C. and Depcik, C. "Review of organic Rankine cycles for internal combustion engine exhaust waste heat recovery", Applied Thermal Engineering, 51(1-2), pp. 711-722 (2013).

68. Lee, D.H., Park, J.S., Ryu, M.R., and Park, J.H. "Development of a highly efficient low-emission diesel engine-powered co-generation system and its optimization using Taguchi method", Applied Thermal Engineering, 50(1), pp. 491-495 (2013).

69. Debnath, B.K., Sahoo, N., and Saha, U.K. "Adjusting the operating characteristics to improve the performance of an emulsified palm oil methyl ester run diesel engine", Energy Conversion and Management, 69, pp. 191-198 (2013).

70. Abedin, M.J., Masjuki, H.H., Kalam, M.A., Sanjid, A., and Ashraful, A.M. "Combustion, performance, and emission characteristics of low heat rejection engine operating on various biodiesels and vegetable oils", Energy Conversion and Management, 85, pp. 173-189 (2014).

71. Chintala, V. and Subramanian, K.A. "Assessment of maximum available work of a hydrogen fueled compression ignition engine using exergy analysis", Energy, 67, pp. 162-175 (2014).

72. Açıkalp, E., Aras, H., and Hepbasli, A. "Advanced exergoeconomic analysis of a trigeneration system using a diesel-gas engine", Applied Thermal Engineering, 67(1-2), pp. 388-395 (2014).

73. Ge, Y., Chen, L., Sun, F., and Wu, C. "FiniteTime Thermodynamic Modelling and Analysis of an Irreversible Otto-Cycle", Appl. Energy, 85, pp. 618624 (2008).

74. Ebrahimi, R. "Thermodynamic modeling of performance of a Miller cycle with engine speed and variable specific heat ratio of working fluid", Computers and Mathematics with Applications, 62, pp. 2169-2176 (2011).

75. Ebrahimi, R. "Effects of mean piston speed, equivalence ratio and cylinder wall temperature on performance of an Atkinson engine", Mathematical and Computer Modelling, 53, pp. 1289-1297 (2011).

76. Ferguson, C.R. "Fuel, air and combustion thermo dynamics", In Internal Combustion Engines-Applied Thermosciences, pp. 103-144, John Wiley \& Sons Inc., New York, USA (1986).

77. Gonca, G., Cakir, M., and Sahin, B. "Performance characteristics and emission formations of a Spark Ignition (SI) engine fueled with different gaseous fuels",
Arabian Journal for Science and Engineering, 43, pp. 4487-4499 (2018).

78. Hohenberg, G., Advanced Approaches for Heat Transfer Calculations, SAE, 790825 (1979).

79. Lin, J., Chen, L., Wu, C., and Sun, F. "Finite-time thermodynamic performance of a dual cycle", Int. J. Energy Res., 23(9), pp. 765-772 (1999).

\section{Biographies}

Guven Gonca received his BS in 2007, MS in 2009, and PhD in 2013 all in Naval Architecture and Marine Engineering from Yildiz Technical University. He also served in a shipyard as a design outfitting engineer for two years and passed two study-abroad semesters in Universita degli Studi di Napoli Federico II, Italy. His MS research project was on detailed design and modelling of ship outfitting. He has been to University of California at Berkeley during 2012-2013 as a visiting researcher. His $\mathrm{PhD}$ thesis subject was on investigation into the effects of steam injection into the turbocharged diesel engine with running Miller cycle on performance and emissions. He worked as Assistant Professor between 2014-2016 and is working as Associate Professor in Naval Architecture and Marine Engineering at Yildiz Technical University.

Yuksel Palaci was graduated as a Metalurgical Engineer from Middle East Technical University. He received his $\mathrm{MS}$ and $\mathrm{PhD}$ degrees in Materials Science from Istanbul Technical University. He has carried out some of his research at TNO-CTK, Netherlands; Penn State University, USA; and IOWA State University, USA. He is mainly experienced in powder processing, injection molding of metal and ceramic powders, and extrusion of alumina ceramics. $\mathrm{He}$ worked at Materials and Chemical Technologies Research Institute for 13 years. Also, he worked in various national/international research projects on powder processing. He worked in Mechanical Engineering Department of Nigde University as Assistant Professor for three and a half years between 2010 and 2013. In 2013, he worked as deputy director in Material Research Institute at TUBITAK. He has been working as Associate Professor in Naval Architecture and Marine Engineering at Yildiz Technical University since 2015. 